\title{
Factor Analysis of Agricultural Innovative Ability in Sichuan Province
}

\author{
Jian Qiang $\mathrm{Li}^{1}$ \\ ${ }^{1}$ College of Economics and Management, Sichuan Agricultural University, Chengdu, China \\ Correspondence: Jian Qiang Li, College of Economics and Management, Sichuan Agricultural University, \\ Chengdu, China. Tel: 86-139-8161-6343. E-mail: 1jq9801@163.com
}

Received: February 14, 2012 Accepted: March 15, 2012 Online Published: June 1, 2012

doi:10.5539/enrr.v2n2p16 URL: http://dx.doi.org/10.5539/enrr.v2n2p16

\begin{abstract}
On the basis of some theories, this paper empirically analyzes on factors that influence the agricultural innovative ability in Sichuan Province by selecting six indices. They are the number of technological person, the financial input of agricultural science and technology, the level of local economic development, the agricultural policy, the number of technologic leaders, and the number of agricultural research institutions. Then I propose some relevant comments. The results indicate that the agricultural policy and the number of technologic leaders strongly influence promoting the innovative capability of agriculture. However, the financial input of agricultural science and technology, the level of local economic development, and the number of agricultural research institutions weakly impact on enhancing the agricultural innovative ability.
\end{abstract}

Keywords: agricultural innovative ability, factors, comments

\section{Introduction}

Innovation is an important mark of national self-reliance and self-strengthening. And it is also an inexhaustible motive force of the prosperity of a country. The report of the 17th Party Congress provided that improving the capability of innovation and building an innovation-oriented country was the core of national development strategies and the key to enhance comprehensive national strength. Moreover, the centre government have put forward that improving the capability of innovation and optimizing the industrial structure are vital historical opportunities to Sichuan. Sichuan is a large population province and a big agricultural province. The weak innovative ability has become a bottleneck to restrict the adjustment of agricultural economic structure and the improvement of farm products competitiveness. To construct modern agriculture and enhance the agricultural comprehensive competitiveness, Sichuan must increase the agricultural innovative capability. And the analysis of its factors is the key.

Nowadays, domestic researchers have studied on agricultural independent innovation by focusing on dimensions such as influence factors, problems of innovation and agricultural product, which has supplied useful revelation and theory references for the current study. In the perspective of influence factors, Ge Bo (2007) systematically analyzed the condition of agricultural scientific innovation in Jilin Province and empirically found out the fundamental factors. Moreover, Li Feng (2006) also empirically studied the factors of innovation from the year of 1990 to 2004 in China.

In the view of problems of innovation, Liu Xu and Wang Xiudong (2007) insisted that it is necessary to perfect the system and mechanism which could solve the such problems that we had. Dong Honglin, Wang Qingfeng (2008) summarized the both domestic and foreign experiences, and pointed out the problems existed in agricultural scientific innovation in China.

In terms of the problem of agricultural products, Rongbing Zhong (2007) showed that it is necessary to enhance the competitiveness of agricultural product through improve the innovation ability, and proposed that we should strengthen the farmer's cognition and widen the financial channel. Xiaoxia Huang (2002) pointed out that to promote the competitiveness of agricultural product must rely on developing science and technology and increase innovative capability.

According to the review of previous literature, we can know that the agriculture capability of innovation of domestic scholars focused largely on qualitative analysis that is a facial phenomenon lacks the deeper explanation of economic problems. Therefore, the paper selects six indices, the number of technologic person, the financial input of agricultural science and technology, the level of local economic development, the 
agricultural policy, the number of technologic leaders, the number of agricultural research institutions. Then it builds an econometric model to analyze the influence degree of each factor that supports the method of increasing innovative capability.

\section{Theoretical Analysis of the Factors}

\subsection{Quantity and Quality of Agricultural Technological Person}

The agricultural technological person who determines the level of regional innovation plays an irreplaceable role in improvement of agricultural innovative capability. It is because the team of agricultural technological person is like a system. Only when all parts of the system interconnect, interact, and mutual restrict, the system can function powerfully. Therefore, according to the experience, the quantity and quality of agricultural technological person positively relates to the agricultural innovative capability of independent innovation, i.e. the more and higher quality of agricultural technological staff causes the higher capability, and vice versa. But if there is no effective incentive and restricted mechanism, an excellent team could hardly work. Even it may have a negatively correlation with the agricultural innovation. That is because the increasing number of technological person would definitely result in the augment of the payment. In this way, the financial input of agricultural innovation would reduce. So, the quantity of technological staff may both have positive and negative correlation with the agricultural innovative ability.

In addition, there is a very close relation between the quantity of technological leaders and the level of the agricultural innovative capability. Technology is the fundamental means of agricultural innovation. And the process of innovation provides technological change and its implementation. The agricultural technological leaders are important discovers of technological opportunities in the innovation, and disseminators of new technological knowledge. They guarantee the new comprehensive productivity and continuously make all kinds of innovation improve. Thus, the more technological leader leads to the higher innovative capability, i.e. the innovative capability positively correlates with agricultural technological leader.

\subsection{Financial Input of Agricultural Science and Technology}

The financial input of agricultural science and technology is a very important part of construction agricultural innovation activity. Many statistic analyses manifest that the investment amount of agricultural technology strongly positively relates with the strength, scale, and level of the innovation. For any agricultural innovation activity, the more financial input causes the higher capability of innovation. That is because each agricultural innovation activity contains many links and processes, like basic research, application research, experimental development, technological development, market development and achievement extension and so on. What is more, to make each link or process totally function, we must invest much fund to build and cultivate. If the financial input lacks, it would make each link of agricultural innovation activity would not work, which affects the effect of the agricultural innovation activity. So according to the experience, positive correlation exists between the investment of technological funds and the capability of agricultural innovation, i.e. more technological funds investments would result in stronger capability of agricultural innovation.

\subsection{Level of Local Economic Development}

The level of regional economic development is also an important factor that impacts on the capability of agricultural innovation. The development of agricultural innovation system needs the support of the local economic development. Moreover, the local economic development is an important material foundation for regional agricultural innovation, and provides environment for local innovation development. The higher level of regional economic development and more investment of agricultural independent innovation would lead to the stronger capability of innovation. Therefore, according to the experience, it is the positive correlation between the level of local economic development and the agricultural innovation.

\subsection{Agricultural Policy}

The agricultural policy provides an appropriate environment to innovation, mainly through establishing the policy of incentive and constraint function and the various benefit mechanism. The benefits, for example, are related preferential policies about tax, financial support, incentive mechanism, property mechanism, constraint mechanism, legal mechanism (the Patent Law, Science and Technology Law, the Law of Agro-technique Extension, the Law of Science and Technology Achievement Transfer etc.). Any inventor's innovation is allowed and supported by the government policy. More related policy of agricultural innovation by the government would cause higher people's enthusiasm for innovation and successful rate of innovation. Therefore, according to the experience, it is the positive correlation between the capability of agricultural innovation and the agricultural policy. 


\subsection{Agricultural Research Institutions}

The agricultural research institutions, which are the main technology cultivation and output regions, play a crucial role in agricultural innovation progress. So, it is the positive correlation between the quantity of the agricultural research institutions and the capability of agricultural innovation. However, in the agricultural research institution system, due to the unbalance among application research, basic research, and the unreasonable resource allocation, the number of agricultural research institution negatively relates to the agricultural innovative ability.

\section{Empirical Analysis of the Factors}

\subsection{Model Construction}

Based on the theories, the paper constructs a multiple regression econometric model to quantitatively analyze factors that influence the agricultural innovation in Sichuan province. The basic model is as follows:

$$
\mathrm{Y}=\mathrm{a}_{1} \mathrm{X}_{1}+\mathrm{a}_{2} \mathrm{X}_{2}+\mathrm{a}_{3} \mathrm{X}_{3}+\mathrm{a}_{4} \mathrm{X}_{4}+\mathrm{a}_{5} \mathrm{X}_{5}+\mathrm{a}_{6} \mathrm{X}_{6}
$$

In the formula, $\mathrm{Y}$ is the result of the agricultural innovative ability in Sichuan province. $\mathrm{X}_{1}$ is the number of technologic person. $\mathrm{X}_{2}$ is the financial input of agricultural science and technology. $\mathrm{X}_{3}$ is the level of local economic development. $\mathrm{X}_{4}$ is the agricultural policy. $\mathrm{X}_{5}$ is the number of technologic leaders. $\mathrm{X}_{6}$ is the number of agricultural research institutions. $a_{1}, a_{2}, a_{3}, a_{4}, a_{5}, a_{6}$ are the regression coefficients of each influence factor.

Table 1. The factors influence the agricultural innovative ability in 2004 and 2006

\begin{tabular}{|c|c|c|c|c|c|c|c|}
\hline Regions & $\mathrm{Y}$ & $\mathrm{X}_{1}$ & $\mathrm{X}_{2}$ & $\mathrm{X}_{3}$ & $\mathrm{X}_{4}$ & $\mathrm{X}_{5}$ & $\mathrm{X}_{6}$ \\
\hline Chengdu2004 & 0.65 & 20120 & 899676 & 18856 & 6 & 11 & 1163 \\
\hline 2006 & 0.835 & 21647 & 1188594 & 22269 & 7 & 13 & 1314 \\
\hline Zigong2004 & 0.208 & 2051 & 57353 & 9075 & 2 & 0 & 353 \\
\hline 2006 & 0.311 & 1474 & 75863 & 11576 & 4 & 0 & 395 \\
\hline Panzhihua2004 & 0.078 & 477 & 94788 & 17883 & 1 & 0 & 126 \\
\hline 2006 & 0.292 & 0 & 115612 & 25539 & 3 & 0 & 102 \\
\hline Luzhou2004 & 0.135 & 1497 & 35459 & 6182 & 2 & 0 & 347 \\
\hline 2006 & 0.173 & 1625 & 68833 & 7819 & 3 & 0 & 353 \\
\hline Deyang2004 & 0.142 & 711 & 99879 & 11442 & 2 & 0 & 165 \\
\hline 2006 & 0.248 & 635 & 190718 & 14724 & 3 & 0 & 189 \\
\hline Mianyang2004 & 0.599 & 2246 & 356675 & 9205 & 5 & 0 & 753 \\
\hline $2006^{\circ}$ & 0.559 & 2449 & 580067 & 11354 & 4 & 0 & 644 \\
\hline Guangyuan2004 & 0.071 & 3154 & 8500 & 4664 & 1 & 0 & 1291 \\
\hline $2006^{\circ}$ & 0.283 & 3564 & 12284 & 6100 & 3 & 0 & 1036 \\
\hline Suining2004 & 0.094 & 1747 & 51119 & 5410 & 1 & 0 & 369 \\
\hline 2006 & 0.281 & 2788 & 35349 & 6762 & 3 & 0 & 368 \\
\hline Neijiang2004 & 0.443 & 2446 & 40207 & 6156 & 4 & 1 & 621 \\
\hline 2006 & 0.724 & 2733 & 29923 & 7598 & 7 & 0 & 604 \\
\hline Leshang2004 & 0.899 & 3272 & 27128 & 7904 & 7 & 0 & 300 \\
\hline 2006 & 0.816 & 959 & 26458 & 10879 & 6 & 0 & 434 \\
\hline Nanchong2004 & 0.815 & 2855 & 31750 & 5101 & 6 & 0 & 571 \\
\hline 2006 & 0.545 & 3770 & 33316 & 6384 & 4 & 0 & 543 \\
\hline Yibing2004 & 0.368 & 3854 & 68533 & 7151 & 4 & 0 & 936 \\
\hline $2006^{\circ}$ & 0.355 & 3896 & 137277 & 9560 & 4 & 0 & 817 \\
\hline Guang'an2004 & 0.26 & 8739 & 1945 & 6081 & 3 & 0 & 4 \\
\hline 2006 & 0.104 & 1795 & 2686 & 7473 & 1 & 1 & 376 \\
\hline Dazhou2004 & 1.462 & 1066 & 5285 & 5720 & 9 & 0 & 91 \\
\hline 2006 & 0.103 & 2365 & 11790 & 7052 & 1 & 0 & 393 \\
\hline Meishang2004 & 0.459 & 1949 & 9337 & 7046 & 4 & 0 & 664 \\
\hline 2006 & 1.078 & 2887 & 24446 & 9201 & 8 & 0 & 567 \\
\hline Ya'an2004 & 0.445 & 1059 & 11916 & 8014 & 4 & 4 & 599 \\
\hline 2006 & 0.489 & 937 & 18246 & 9828 & 4 & 6 & 470 \\
\hline Bazhong2004 & 0.244 & 2054 & 1636 & 4161 & 2 & 0 & 806 \\
\hline 2006 & 0.097 & 1706 & 5370 & 4705 & 1 & 0 & 413 \\
\hline Ziyang2004 & 0.173 & 3756 & 14748 & 5608 & 3 & 0 & 570 \\
\hline 2006 & 0.043 & 3260 & 30637 & 7049 & 1 & 0 & 649 \\
\hline A'ba2004 & 0.034 & 1230 & 2053 & 7126 & 2 & 0 & 409 \\
\hline 2006 & 0.008 & 1430 & 5957 & 9758 & 1 & 0 & 352 \\
\hline Ganzi2004 & 0.183 & 1101 & 1491 & 4615 & 2 & 0 & 324 \\
\hline 2006 & 0.183 & 1262 & 1896 & 6452 & 2 & 0 & 296 \\
\hline Liangshang2004 & 0.445 & 0 & 3741 & 5803 & 4 & 0 & 193 \\
\hline 2006 & 0 & 3151 & 11726 & 8331 & 2 & 0 & 208 \\
\hline
\end{tabular}




\subsection{Variable Declaration and Data Sources}

The Y, the capability of agricultural innovation in Sichuan province, is selected by some indices, such as the number of new rice varieties validation, the number of new maize varieties validation, the number of new wheat varieties validation, the number of agricultural science and technology awards of Sichuan, and the number of papers published in core journals of Sichuan agriculture. Then these indices are studied by comprehensive evaluation method and analytic hierarchy process (AHP). To consider unavailability of data, the paper substitutes the social financial input of science and technology, per capita GDP in each region, the number of agricultural science and technology services respectively for the financial input of agricultural science and technology, the level of regional economic development, and the number of agricultural research institutions. Because the number of policy of agricultural innovation of each region cannot be directly calculated, this paper uses scoring method to evaluate, according to how many pieces policies about agricultural innovation have been published of Sichuan Province. The specific rules are as follows: The total score are 10 points; the number of policy from $0 \sim 3$ is equal to the score of $0 \sim 3$; the number of policy from $4 \sim 6$ is equal to the score of $4 \sim 6$; the number of policy from $7 \sim 10$ is equal to the score of 7 10. It must be noted here that the number of policy of agricultural innovation is less than the score of 10 .

Considering 2005 is the last year of " 15 program", there are many fluctuations in many aspects than any other year, such as policy, plans, goals, which may obviously impact on measurement results. So the paper selects data of 2004 and 2006 in each region of Sichuan province to analyze. Table 1 summaries the data sources which come from the Statistical Yearbook of Sichuan Province, Rural Statistical Yearbook of Sichuan Province and related information.

\subsection{Results of Model Estimation}

The paper analyzes the Panel Data by constant slope variable intercept fixed effect model and Eviews3.1 econometric software. The result exists in Table 2. It implies that the adjusted $\mathrm{R}^{2}=0.99, \mathrm{~F}=13576.45$, and all variables are tested by statistics, i.e. the influence of a single independent variable is significant. So the model is significant with explanatory power.

Table 2. The model estimation result of the factors in Sichuan Province

\begin{tabular}{cccc}
\hline & \multicolumn{3}{c}{ Fixed Effect Model } \\
Explanatory variables & $\begin{array}{c}\text { Expected } \\
\text { symbol }\end{array}$ & $\begin{array}{c}\text { Estimated } \\
\text { value }\end{array}$ & $\begin{array}{c}\text { T-test } \\
\text { value }\end{array}$ \\
\hline $\mathrm{X}_{1}$ & $+/-$ & $-8.90^{*}$ & -2.8 \\
$\mathrm{X}_{2}$ & + & $2.22^{*}$ & 3.41 \\
$\mathrm{X}_{3}$ & + & $-1.09^{*}$ & -4.04 \\
$\mathrm{X}_{4}$ & + & $0.12^{* * *}$ & 34.66 \\
$\mathrm{X}_{5}$ & + & $0.03^{* * *}$ & 24.02 \\
$\mathrm{X}_{6}$ & $+/-$ & $5.85^{*}$ & 5.05 \\
Adjusted R-square & & 0.99 \\
F-statistic & \multicolumn{3}{|}{13576.45} \\
\hline$*$ is $10 \%, 5 \%, 1 \%$ of the level of statistical significance test respectively.
\end{tabular}

In the estimation result, first and foremost, the number of technological person negatively impacts on the agricultural innovative ability. The financial input of agricultural science and technology, the agricultural policy, the number of technologic leaders, and the number of agricultural research institutions have positive effects on the capability of agricultural innovation. Excluding the level of local economic development, the coefficient of the other independent variables coincides with my expectation. Furthermore, the agricultural policy and the number of technologic leaders remarkably effect on the capability of agricultural innovation. It expresses that these two variables plays a significant role in improving the capability of agricultural innovation.

Additionally, although the variable of technologic person is tested by statistics and the coefficient is negative and 
accords with the expectation, this result points that more number of technologic people would cause lower capability of agricultural innovation. The reason of this phenomenon may be the uneven quality of technological person and the low effective agricultural institutions. So there is a shortage of agricultural technological person who can boost the capability of agricultural innovation.

Thirdly, the evaluation result does not coincide with the expectation, though the variable of local economic development is tested by statistics. There are two possible explanations. One possible explanation is that the payment of agricultural technological person is low, which directly decides the work enthusiasm of agricultural innovation. Another possible explanation is that the local government pays inadequate attention on agriculture.

\section{Conclusion and Comments}

The level of agricultural innovative ability is the interaction of the number of agricultural technologic person, the financial input of agricultural science and technologic, the level of local economic development, agricultural policy, and agricultural research institutions. From the result of econometric study, the number of agricultural technological person negatively affects on the agricultural innovative ability. By contrast, the financial input of agricultural science and technology, agricultural policy, number of technological leaders, and number of agricultural research institutions, positively influence the agricultural innovative ability. Particularly, the agricultural policy and agricultural technological leaders notably influence the capability of agricultural innovation. It hints that the agricultural policy and agricultural technological leaders play important roles in agricultural innovative ability.

Therefore, if we want to improve the capability of agricultural innovation in Sichuan province, we must firstly buttress the financial input of agricultural science and technology. Secondly, we must reinforce the construction of agricultural scientific and technological person, especially the agricultural and technologic leaders. Thirdly, according to the reality, we must establish a better system of agricultural science and technology policy. Ultimately, we must intensify the institution reform of agricultural scientific and technological organizations.

\section{References}

Dai, D. F. (2007). The Factor and Countermeasures on Regional Independent Innovation Ability in Jiangsu Province. Journal of Adult Education of Gansu Political Science and Law Institute, 2, 115-116.

Dong, H. L., \& Wang, Q. F. (2008). Ningxia Journal of Agriculture and Forestry Science and Technology, 2 , 33-35.

Huang, X. X. (2002). Rely on Progress of Science and Technology, Enhance Competition Power of Agricultural Products. Journal of Huizhou Univerisity, 5, 472-474.

Joseph., A. S. (1997). The theory of Economic Development. Beijing: The Commercial Press. Coe, Helpman, Hoffmaister. North-south spill over. Economic Journal, 134-149.

Li., F. (2006). The empirical analysis of the factor influencing in the ability of independent innovation in China. Forum of World Economics \& Politics, 5, 33.

Xu, L., \& Wang, X. D. (2007). Consummating input system and mechanism, pushing forward capacity building for independence innovation in agricultural science and technology. Issues in AgriculturalEconomy, 3, 24-30.

Zhao, P. S., \& Ma, E. B. (2005). A Research Report about the ability of independent innovation improving. High-Technology \& Industuialigation, 7, 29-31.

Zhong, R. B. (2007). Strengthen Agriculture Independent Innovation Improve the Competition Ability of Farm Produce. Journal of Hunan University of Science and Engineering, 1, 94-96. 